\title{
Till tolkningen av runföljden huli (U 604)
}

\author{
Patrik Larsson (Dalarna University)
}

\begin{abstract}
The inscription on the runestone from Stäket in Uppland (U 604) begins with an uninterpreted runic sequence, huli, which clearly denotes a male personal name. A consideration of the orthography of the inscription as well as onomastic parallels allows a number of possible interpretations to be discussed. The interpretation deemed most likely identifies the rune sequence huli as a name, Runic Swedish Hulli, connected to the Old Swedish adjective hulder, meaning either 'huld, välsinnad, trogen, tillgifven; kär; benägen (för), hängifven (åt); trogen, god' ('fair, well meaning, faithful, affectionate, in love, inclined (to), good' or similar) or 'vid hull, hullig' ('fleshy' or similar). The name Hulli could therefore be translated as 'the well meaning, the faithful' or 'the fleshy, the fat' or the like.
\end{abstract}

Keywords: Runic inscriptions, Viking Age, personal names, Stäket, U 604

$\mathrm{D}$ en delvis bevarade runstenen U 604 från Stäket, Stockholms-Näs sn (nu Kungsängen; se fig. 1), bär en inskrift som Elias Wessén (i SRI, 8: 3) återgivit på följande sätt (med normaliseringen anpassad efter Peterson 2006 och 2007):

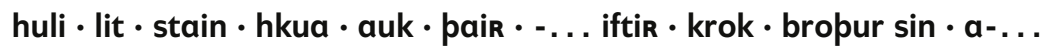

huli lēt stæin haggva ok pæin ... æftiR Krōk, brōður sinn ...

'huli lät hugga stenen och ... efter Krok, sin broder ...'

Den inledande runföljden huli, som av kontexten att döma (särskilt pronomenformen pæiR pl. m. nom. 'de') måste avse ett mansnamn i nominativ, kommenteras ganska kortfattat. Wessén konstaterar (i SRI, 8: 4) att samtliga runor "äro fullt säkra", och de tre äldre läsningar som anförs (Hadorph och Helgonius, Celsius och Dybeck) är samstämmiga på den

Larsson, Patrik. "Till tolkningen av runföljden huli (U 604)." Futhark: International fournal of Runic Studies 9-10 (2018-2019): 193-200. English: "On the interpretation of the runic sequence huli (U 604)" DOI: $10.33063 /$ diva-401051 


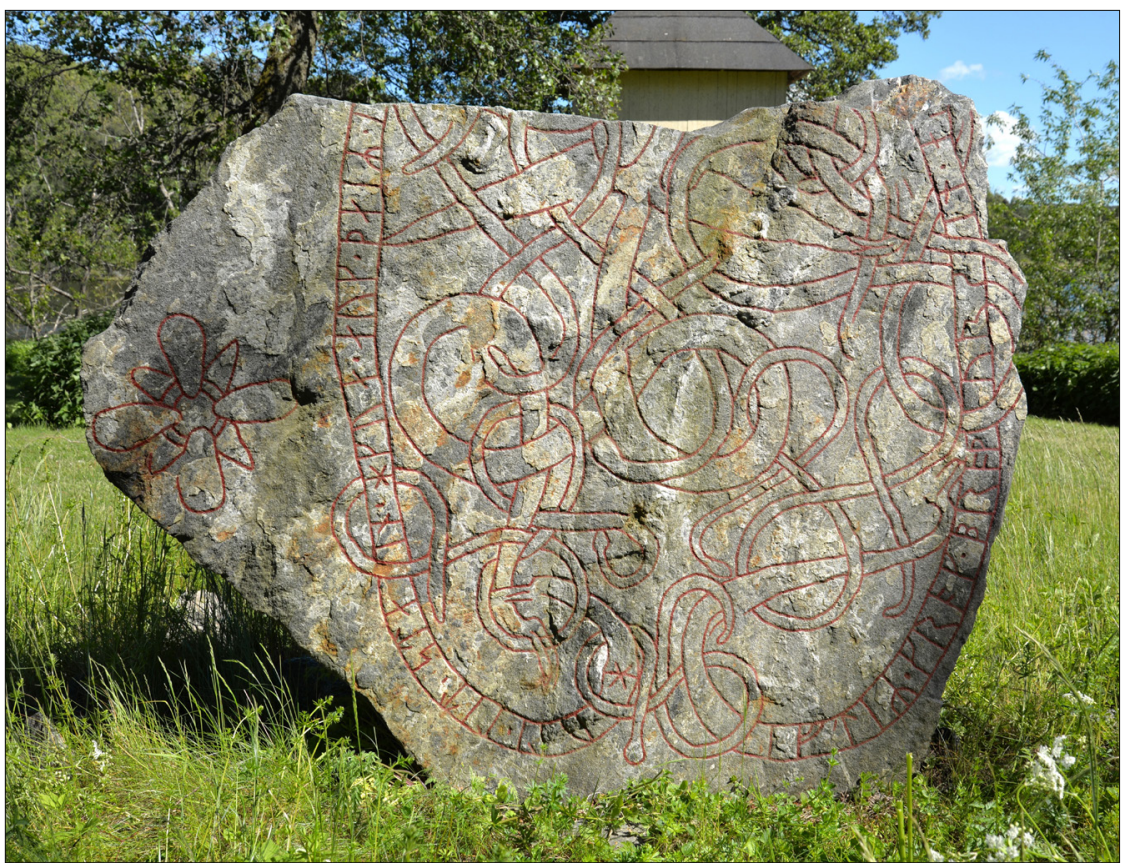

Fig. 1. Runstenen U 604 från Stäket. Foto: kulturbilder.wordpress.com.

punkten. Beträffande tolkningen ger Wessén endast följande, lakoniska kommentar: "Ett mansnamn huli är f.ö. okänt, såväl i inskrifterna som i andra källor."

Stenen är, såvitt jag kunnat se, inte attribuerad till någon känd ristare (den nämns exempelvis inte i Axelson 1993, Stille 1999 eller Källström 2007). Den har dock påfallande likheter med en del andra stenar, exempelvis U 294, U 295 och U 305, och i ett opublicerat manuskript (Stille ms.) har Per Stille sammanfört U 604 med inte mindre än dryga trettiotalet andra inskrifter, vilka han menar samtliga är utförda av samma ristare, Sven (då det finns flera ristare med detta namn kallar Stille den här aktuelle ristaren för Sven Mällösa; om ristare med namnet Sven, se också Axelson 1993, 6, 63-65). ${ }^{1}$ Runristare med namnet Sven vore värda en egen undersökning, och även om man inte godtar samtliga av Stilles attribueringar

\footnotetext{
${ }^{1}$ Stille anför följande 35 inskrifter som verk av Sven: U 102, U 114, U 116, U 206 †, U 211, U 239, U 244, U 246, U 247, U 248, U 249, U 251, U 253, U 270, U 277, U 280, U 284, U 294, U 295, U 304, U 305, U 306, U 313, U 317 †, U 318, U 319, U 320 †, U 321, U 373, U 604, U 983, U THS10;58, U Fv1959;188, U Fv1971;209, U Fv1986;84 och U Fv1993;233. För förklaringar av signumen, se Samnordisk runtextdatabas.
} 
förefaller det klart sannolikt att U 604 inte ska betraktas som ett isolerat monument vad gäller upphovsman, utan att det kan sammanhållas med ett flertal andra inskrifter, bland annat på ortografiska, syntaktiska och stilmässiga grunder.

Vad gäller tolkningen av runföljden huli är det framför allt u-runan som är av intresse, och då exempelvis om den skulle kunna beteckna /o(:)/ samt förekomsten eller avsaknaden av stungna runor. I inskriften U 604 förekommer /o:/ två gånger (ack. Krōk, ack. brōður), båda ristade med åsruna (o), varför det förefaller mindre troligt att $\mathbf{u}$-runan i huli skulle representera just /o:/. Detta bekräftas också av den bild de av Stille sammanförda inskrifterna ger, där /o(:)/ konsekvent tycks betecknas med o-runa. I U 604 förekommer inga stungna runor, men om hänsyn tas till de inskrifter Stille sammanställt framgår det att stungen u-runa (y) finns i ristaren Svens repertoar. Bilden är dock inte entydig: i de inskrifter som är relevanta att jämföra, dvs. sådana där stungen u-runa skulle kunna förekomma, används u i tre inskrifter (U 102, U 373 och U THS10;58), y i fyra (U 116, U 270, U 304 och U 320 †; de två sistnämnda måste dock betraktas som osäkra, då de härrör från en otolkad runföljd respektive en försvunnen inskrift) och i en inskrift (U 114) används båda. Med andra ord går det inte att utesluta att $\mathbf{u}$-runan i huli skulle kunna beteckna exempelvis $/ y(:) /$ eller $/ \varnothing(:) /$, även om det, med tanke på att möjligheten att i så fall stinga u-runan tycks ha stått ristaren till buds, förefaller något troligare att den betecknar $/ \mathrm{u}(:) /$.

Som Wessén påpekat (se ovan) är något namn som otvunget går att sammanställa med runföljden huli inte känt. En eventuell möjlighet skulle dock vara om det gick att sammanhålla runföljden huli med binamnet fornsvenska (härefter fsv.) Hol, Hole, Holi (SMPs); hur detta ska uppfattas är dock inte självklart, men det skulle kunna höra samman med fsv. huln. 'hål, öppning; håla' eller med adjektivet fsv. hul 'ihålig' (Söderwall 18841918, 1: 518). Några direkta semantiska paralleller till ett sådant namn står dock inte till buds, vad jag kan se, vilket gör ett sådant antagande mindre tilltalande. En annan möjlig koppling till känt namnmaterial vore om det gick att anknyta till binamnet fornvästnordiska (härefter fvn.) Hólmuðr, av fvn. hól n. 'skryt'; jfr Hólbarki 'strupe' (Lind 1920-21, sp. 153 resp. 152). Det skulle förutsätta en bildning direkt till ordet fvn. hól n. 'skryt', vilket kanske vore möjligt. Eftersom fvn. hól etymologiskt innehåller vokalen /o:/ (de Vries 1962, 247) skulle det dock också innebära att u-runan i huli betecknar /o:/, vilket ovan framhållits som osannolikt, varför denna tolkningsmöjlighet inte heller framstår som särskilt tilltalande. I det följande kommer jag därför att försöka lyfta fram några alternativ. 
En första möjlighet vore att tolka huli som ett namn Hulli, vilket vore identiskt med den bestämda formen av adjektivet fsv. hulder 'huld, välsinnad, trogen, tillgifven; kär; benägen (för), hängifven (åt); trogen, god' (Söderwall 1884-1918, 1: 518 f.), fvn. hollr 'holl, tru, pålitelig; velvillig, godhuga, nådig' (Heggstad, Hødnebø och Simensen 1993, 196), 'hengiven, velsindet, huld, tro mod en; saadan at man deri eller derved viser sin oprigtige Velvilje og Troskab' (Fritzner 1886-96, 2: 36). ${ }^{2}$ Värt att nämna i detta sammanhang är också ett uttryck på en av Hällestadstenarna från Skåne (DR 295), som är rest till minne av Toke, Gorms son, vilken av stenresaren ges det berömmande epitetet $s_{\bar{e}}$ hullan drōttin ('sin trogne herre' eller liknande). Ordet fsv. hulder förekommer också med en annan betydelse, nämligen 'vid hull, hullig' (Söderwall 1884-1918, 1: 519), fvn. holdr 'holda' (jfr även fvn. holdugr 'kjøtfull, i godt hold'; Heggstad, Hødnebø och Simensen 1993, 196), vilket också är av intresse.

Den andra tolkningsmöjligheten jag vill lyfta fram är Hylli, identiskt med fsv. hylle f. 'huldhet, trohet, ynnest, nåd', även n. (Söderwall 18841918, 1: 543, Söderwall Supplement, 326), fvn. hylli f. 'vennskap, velvilje, kjærleik' (Heggstad, Hødnebø och Simensen 1993, 215), 'Velvilje, Yndest' (Fritzner 1886-96, 2: 150; även en variant med neutralt genus förekommer, liksom hylla f., med samma betydelse).

En tredje möjlighet skulle också kunna komma i fråga, nämligen $H y l i$, en an-stamsbildning till fsv. hyl m. och f. 'med vatten fyld fördjupning, djup vattensamling, djup' (Söderwall 1884-1918, 1: 543), fvn. hylr m. 'høl, kulp' (Heggstad, Hødnebø och Simensen 1993, 215), 'Høl, dyb Vandsamling af mindre Omfang, især saadan som danner sig i Elv nedenunder et Vandfald, hvor Vandet ligesom standser og samler sig for derfra igjen at strømme videre' (Fritzner 1886-96, 2: 150).

Vad gäller den onomastiska anknytningen kan det konstateras att den är svag för alla tre förslagen. Sett till namnens bildning är alternativ 1 (Hulli) och 3 (Hyli) oproblematiska, medan alternativ 2 (Hylli) är mer tveksamt. Det skulle då röra sig om en inn-stam med abstrakt betydelse, vilket förefaller att vara högst ovanligt. Ett välbekant exempel är dock det mytologiska namnet fvn. Elli 'ålder' (Lind 1905-15, sp. 232), men

\footnotetext{
${ }^{2}$ Här bör påpekas att tolkningen Hulli, med anknytning till fsv. hulder 'huld, välsinnad, trogen, tillgifven; kär; benägen (för), hängifven (åt); trogen, god', också har föreslagits av Henrik Williams (Williams ms.). Motsättningen mellan [1:] i Hulli och [ld] i hulder beror på att i det senare ordet har ett inskott av [d] skett mellan [1:] $(<$ [lp]) och [r]; vokalen i ändelsen är ett senare inskott, en s.k. svarabhaktivokal (Wessén 1968 § 26, 41, 53 anm. 2). I Hulli föreligger dock inte de fonetiska förutsättningarna för ett sådant inskott (jfr exempelvis ack. hullan i DR 295).
} 
det har sin särskilda förklaring, då det rör sig om ett symboliskt namn på en gumma som representerar själva ålderdomen. Det finns dock ett antal fornsvenska binamn som skulle kunna vara av intresse i detta sammanhang: Blidhe, Blinde, Døve, Gire, Milde och Starke (SMPs). Dessa kan jämföras med följande fornsvenska in-stamsbildningar med abstrakt betydelse: blidhe 'blidhet, mildhet', blinde 'blindhet', døve 'dövhet', giri 'begär, lust, girighet m.m.', milde 'mildhet', starke, sidoform till stærke 'styrka, kraft, makt' (Olson 1916, 429 f.). Nu är det dock betydligt mer sannolikt att de fornsvenska binamnen ska uppfattas som svagt böjda adjektiv, särskilt med tanke på att sådana är mycket frekventa bland just binamn (Ekbo 1947, 271 f.). Utifrån namnbildningsperspektivet framstår därför tolkningsalternativet Hylli som mindre sannolikt.

Om vi vänder blicken mot semantiska paralleller till de föreslagna tolkningarna går sådana att anföra till alternativ 1 (Hulli) och 2 (Hylli), medan det är mer tunnsått vad gäller alternativ 3 (Hyli). Visst går det att hitta exempel på binamn med anknytning till vatten, såsom fvn. Austan ár och Austan siór (Lind 1920-21, sp. 10), men dessa är lokalitetsangivande och därför inte jämförbara med betydelserna hos fsv. $h y l \mathrm{~m}$. och f. och fvn. hylr m. ('med vatten fyld fördjupning, djup vattensamling, djup', 'høl, kulp' etc.). Till betydelsesfären 'huld, välsinnad, trogen, tillgifven; kär; huldhet, trohet, ynnest, nåd' etc. går det betydligt enklare att hitta paralleller, till exempel de i runinskrifter förekommande $G \bar{o} ð i$, av bestämda formen av adj. (fvn.) góðr'god', Trōfastr (?), av adj. (fvn.) trúfastr'trofast, pålitlig, fast i tron', Tryggr, av adj. (fvn.) tryggr 'trofast, pålitlig' (Peterson 2007) och binamnet fsv. Kærlek 'kärlek' (Hellquist 1912, 102). Paralleller till betydelsen hos fsv. hulder'vid hull, hullig' är också rikligt förekommande, såsom de i runinskrifter belagda Bōfi, av * boofi m. 'tjock och klumpig person', Bōsi, av (fvn.) bósi m. 'fyllig, knubbig karl', Fæitr(?), av adj. (fvn.) feitr'fet' och PiqkkR, av adj. (fvn.) pjokkr 'tjock' (Peterson 2007). För ytterligare exempel på namn som ansluter till den här aktuella betydelsen, se Larsson 2000, 17 f. med not 13, 2002, 34 och i dessa arbeten anförd litteratur.

För att summera: av de tre diskuterade förslagen till tolkning av runföljden huli, 1) Hulli, 2) Hylli och 3) Hyli, finns det betänkligheter mot alternativ 2 vad gäller namnbildningen och mot alternativ 3 vad gäller semantiska paralleller. För båda gäller också att hade namnet innehållit /y/ hade möjligen en stungen $\mathbf{u}$-runa $(\mathbf{y})$ varit mer förväntad, även om det inte är en tvingande invändning. Sammantaget menar jag dock att både alternativ 2 och 3 bör stå tillbaka till förmån för alternativ 1, Hulli. Den enda komplikationen gällande det alternativet är att fastställa namnets innebörd, då det finns två möjligheter, dvs. adjektivet fsv. hulderi antingen be- 
tydelsen 'huld, välsinnad, trogen, tillgifven; kär; benägen (för), hängifven (åt); trogen, god' eller 'vid hull, hullig'. Att fälla ett avgörande mellan dessa är inte utan sina svårigheter, då det finns skäl som talar för båda: hulder i betydelsen 'huld, välsinnad etc.' är betydligt bättre belagt i fornsvenskan, medan de semantiska parallellerna till hulder i betydelsen 'vid hull, hullig' är betydligt fler. Med andra ord menar jag att det är mycket som talar för att runföljden huli ska tolkas som ett namn Hulli, men om detta ska översättas med 'den hulde, den välsinnade, den trogne el. likn.' eller med 'den hullige, den tjocke, den fete el. likn.' är som sagt svårt att säkert avgöra, varför frågan måste lämnas öppen.

Efter den företagna undersökningen menar jag att inskriften U 604 kan återges på följande sätt:

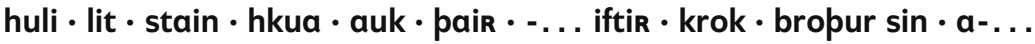

Hulli lēt stæin haggva ok pæin ... æftiR Krōk, brōður sinn ...

"Hulle lät hugga stenen och ... efter Krok, sin broder ..."

\section{Bibliografi}

Axelson, Jan. 1993. Mellansvenska runristare: Förteckning över signerade och attribuerade inskrifter. Runrön, 5. Uppsala.

$\mathrm{DR}+\mathrm{nr}=$ inskrift publicerad i Danmark runeindskrifter, av Lis Jacobsen och Erik Moltke, 3 vol.: Text; Atlas; Registre (København, 1941-42).

Ekbo, Sven. 1947. "Nordiska personbinamn under vikinga- och medeltid." I Personnamn, utg. av Assar Janzén, 269-84. Nordisk kultur, 7. Stockholm, Oslo och København.

Fritzner, Johan. 1886-96. Ordbog over det gamle norske Sprog. 2. utg. 3 vol. Kristiania. Rettelser og tillegg. Av Finn Hødnebø. Oslo, 1972.

Heggstad, Leiv, Finn Hødnebø och Erik Simensen. 1993. Norrøn ordbok. 4. utg. av Gamalnorsk ordbok vid Marius Hægstad och Alf Torp. Oslo.

Hellquist, Elof. 1912. "Fornsvenska tillnamn." I Xenia Lideniana: Festskrift tillägnad professor Evald Lidén på hans femtioårsdag den 3 oktober 1912, 84-115. Stockholm.

Källström, Magnus. 2007. Mästare och minnesmärken: Studier kring vikingatida runristare och skriftmiljöer i Norden. Acta Universitatis Stockholmiensis, Stockholm Studies in Scandinavian Philology, n.s., 43. Stockholm.

Larsson, Patrik. 2000. "Ett problematiskt personnamn: Till tolkningen av runföljden kus i tre uppländska inskrifter." Studia anthroponymica Scandinavica 18: 5-23.

— . 2002. ”Det fornvästnordiska personbinamnet Kíkr." Scripta Islandica 53: 29-38.

Lind, E. H. 1905-15. Norsk-isländska dopnamn ock fingerade namn från medeltiden. Uppsala. Supplementband. Av E. H. Lind. Oslo, Uppsala och København, 1931. 
—. 1920-21. Norsk-isländska personbinamn från medeltiden. Uppsala.

Olson, Emil. 1916. De appellativa substantivens bildning i fornsvenskan: Bidrag till den fornsvenska ordbildningsläran. Lund.

Peterson, Lena. 2006. Svenskt runordsregister. 3. rev. uppl. Runrön, 2. Uppsala.

—. 2007. Nordiskt runnamnslexikon. 5. rev. utg. Uppsala.

Samnordisk runtextdatabas. Institutionen för nordiska språk, Uppsala universitet. http://www.nordiska.uu.se/forskn/samnord.htm

SMPs = Samlingarna till Sveriges medeltida personnamn, Institutet för språk och folkminnen, Uppsala.

$S R I=$ Sveriges runinskrifter. Olika författare; publicerade av Kungl. Vitterhets Historie och Antikvitets Akademien. 14 vol. hittills. Stockholm, 1900-.

SRI, 6-9 = Upplands runinskrifter, av Elias Wessén och Sven B. F. Jansson (1940-58).

Stille, Per. 1999. Runristare och runristare $i$ det vikingatida Fjädrundaland: En studie $i$ attribuering. Runrön, 13. Uppsala.

—. ms. "Sven - fyra uppländska runristare." Opublicerat manuskript.

Söderwall, Knut Fredrik. 1884-1918. Ordbok öfver svenska medeltids-språket. 3 vol. Lund. Supplement. Av Knut Fredrik Söderwall, Walter Åkerlund, Karl Gustaf Ljunggren och Elias Wessén. 2 vol. Lund, 1925-73.

$\mathrm{U}+\mathrm{nr}=$ inskrift publicerad i Upplands runinskrifter, dvs. SRI, 6-9.

de Vries, Jan. 1962. Altnordisches etymologisches Wörterbuch. 2. utg. Leiden.

Wessén, Elias, 1968. Svensk språkhistoria, vol. 1: Ljudlära och ordböjningslära. 8. uppl. Nordiskt kursbibliotek. Stockholm.

Williams, Henrik. ms. ”U 604 huli.” Opublicerat manuskript.

\section{English Summary}

On the interpretation of the runic sequence huli (U 604)

The inscription on the partly damaged runestone from Stäket in Uppland ( $\mathrm{U}$ 604; see fig. 1) is to be read, normalized and translated as follows, according to Elias Wessén (in SRI, 8: 3; the English translation is taken from Samnordisk runtextdatabas):

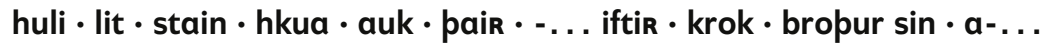

huli lèt stæin haggva ok pæiR ... æftiR Krōk, brōður sinn ...

'huli lät hugga stenen och ... efter Krok, sin broder ...'

'huli and ..., they had the stone cut ...... in memory of Krókr, their brother ...'

The inscription begins with the uninterpreted runic sequence huli which, given the context of the inscription, clearly denotes a male personal name. The orthography of the inscription, as well as that of a number of further inscriptions that could very well be by the same carver, Svæinn, is 
discussed, showing that it is unlikely that the u-rune represents /o(:)/ and that the most likely alternative is $/ \mathrm{u}(:) /$. Some possible interpretations are discussed, and the one deemed most likely is to read the runic sequence huli as the Runic Swedish name Hulli, connected to the Old Swedish adjective hulder, meaning either 'huld, välsinnad, trogen, tillgifven; kär; benägen (för), hängifven (åt); trogen, god' ('fair, well meaning, faithful, affectionate, in love, inclined (to), good' or similar) or 'vid hull, hullig' ('fleshy' or similar). The name Hulli could therefore be translated as 'the well meaning, the faithful' or 'the fleshy, the fat' or the like. In Old Swedish, the word hulder is better attested as meaning 'well meaning, faithful, affectionate, in love, inclined (for), good' and the like than as 'fleshy' and the like. On the other hand, onomastic parallels to the latter are more frequent. A definitive conclusion is therefore hard to reach. The present study shows, however, that the first word (name) in the inscription can likely be rendered as Old Swedish Hulli, modern Swedish Hulle, and English (in the Old West Norse form) Hulli. 